\title{
Relationship between delayed menarche and bone density in patients affected by juvenile idiopathic arthritis
}

\section{A Lurati*1, A Salmaso ${ }^{2}$, B Teruzzi ${ }^{2}$, V Gerloni ${ }^{2}$, M Gattinara ${ }^{2}$ and F Fantini ${ }^{2}$}

Address: ${ }^{1}$ Fornaroli Hospital Rheumatology Unit, Magenta, Italy and ${ }^{2}$ Gaetano Pini Institute Chair of Rheumatology, Milan, Italy

* Corresponding author

from $15^{\text {th }}$ Paediatric Rheumatology European Society (PreS) Congress

London, UK. 14-17 September 2008

Published: 15 September 2008

Pediatric Rheumatology 2008, 6(Suppl I):P45 doi:I0.I 186/I546-0096-6-SI-P45

This abstract is available from: http://www.ped-rheum.com/content/6/SI/P45

(c) 2008 Lurati et al; licensee BioMed Central Ltd.

The aim of our study was to prospectively evaluate bone density in adolescents females with JIA, and to correlate the results with puberty. Lumbar spine (L2-L4) areal bone mineral density (aBMD) (assessed by Dual X-ray Absorbiometry, DXA) was monitored every 6-12 months in a group of 38 girls with JIA. The evaluated bone density accrual during the peripubertal time as well as absolute and relative (Z-score) aBMD in relationship with age at menarche, JIA subset, disease activity, corticosteroid and methotrexate treatment was assessed. Height, body mass index, Bone Mass Content values were also collected. Volumetric BMD evaluated with a geometric correction formula has been calculated and compared to aBMD.

Patients were divided into two groups:

- group I included girls with menarche age within normal limits for italian standards;

- group II included girls with delayed menarche. The BMD values and $Z$ scores in group I were not significantly different to normal population. The BMD values and $Z$ scores in group II were significantly decreased when compared to the normal population $(\mathrm{p}<0.001)$. With a multivariate analysis only age at menarche seemed independently related to peripubertal mineralization $(\mathrm{p}=0.025, \mathrm{r}$ between -0.65 and -0.75 ). With a binary logistic analysis only disease activity (ESR and Hgb values) seems independently related to a menarche delay $(1.24 \pm 0.4$ for each $\mathrm{mm} / \mathrm{h}$ ). Our data show a critical role for disease activity in determination of a regular pubertal onset and an optimal bone density achievement. 